\title{
PROJETO CARTOGRÁFICO PARA REPRESENTAÇÃO TRIDIMENSIONAL DE REDES DE ENERGIA
}

\author{
Cartographic design for 3D representation of electric power network \\ SUZANA DANIELA ROCHA SANTOS \\ LUCIENE STAMATO DELAZARI \\ MARIA CECILIA BRANDALIZE \\ Universidade Federal do Paraná \\ Setor de Ciências da Terra \\ Programa de Pós-Graduação em Ciências Geodésicas \\ CEP: 81.990 - Centro Plitécnico-Curitiba - Brasil \\ suzanadrs@hotmail.com; luciene@ufpr.br; Maria.brandalize@ufpr.br
}

\begin{abstract}
RESUMO
Neste artigo apresenta-se um projeto cartográfico para representação tridimensional de redes de energia elétrica. Até o momento existem poucas pesquisas relacionadas ao projeto de mapas tridimensionais, considerando principalmente a adequação da simbologia ao propósito do mapa. Grande parte dos mapas tridimensionais é produzida considerando os mesmos aspectos utilizados para os mapas bidimensionais, o que muitas vezes, pode ocasionar problemas no resultado final, e consequentemente, na forma de uso. Deste modo, a partir das etapas descritas por Sluter (2008) e por Haeberling (2008) para projetos cartográficos bi e tridimensionais, respectivamente, foi realizada uma análise das diferenças entre ambos. A partir desta análise, verificou-se que a principal mudança está relacionada à proposição da simbologia. Considerando este aspecto, neste trabalho apresenta-se o projeto cartográfico realizado para geração de uma representação tridimensional para redes de energia elétrica. Foram propostas duas simbologias distintas realística e geométrica - que foram aplicadas ao modelo tridimensional da área de estudo e como resultado obteve-se a melhor adequação dos símbolos geométricos na diferenciação dos elementos das redes.
\end{abstract}

Palavras-chave: Projeto Cartográfico; Representação Tridimensional.

\section{ABSTRACT}

This paper presents a cartographic design for $3 \mathrm{D}$ representation of electric power networks. So far, there are few research works related to 3D cartographic design, 
mainly considering the suitability of symbology to map use. Most 3D maps are produced considering the same aspects used to design 2D maps and this can lead to problems in the final product and, consequently, in the way maps are used. Hence, using as reference the cartographic design for 2D and 3D maps proposed by Sluter (2008) and Haeberling (2008), respectively, the existent differences between them were analyzed. As a result of this analysis it was noticed that the main change is related to symbology desing. Afterward, this paper presents two different proposals of symbology: one realistic and other geometric. These two symbologies were applied to the study area and the results point out to better differentiation of network elements when geometric symbols were used.

Keywords: Cartographic Design, Three-Dimensional Representation.

\section{INTRODUÇÃO}

Os mapas tridimensionais estão sendo usados nas mais diferentes áreas do conhecimento e para os mais diversos fins. No contexto da engenharia elétrica esses mapas estão sendo utilizados para estudos de manutenção das redes, identificação de áreas com perda de energia e avaliação de áreas de segurança, conforme apresentado em Nero et al (2010). O problema encontrado é a falta de princípios para sua elaboração e a falta de padronização da simbologia, ou seja, faltam princípios cartográficos na criação desses mapas tridimensionais, o que prejudica e compromete o processo de comunicação cartográfica. Entretanto, na literatura sobre o assunto ainda são poucas as pesquisas acerca das melhores formas de representar o mundo de forma tridimensional. Algumas iniciativas podem ser vistas em Nero et al (2010), Zlatanova (2003), entre outros.

A falta de princípios cartográficos e estudos científicos de como elaborar mapas e símbolos tridimensionais muitas vezes acarreta o uso inadequado dessa forma de representação. Com isso, os mapas tridimensionais são produzidos em função do bom senso do cartógrafo e, geralmente, sem fazer uso de uma simbologia adequada, sem considerar os aspectos gráficos do mapa e as necessidades do usuário. $\mathrm{O}$ estabelecimento de tais princípios cartográficos para geração de mapas tridimensionais constitui uma base indispensável para a elaboração destes produtos voltados para qualquer grupo de usuários.

Neste trabalho serão avaliadas as questões relacionadas ao projeto cartográfico tridimensional e será apresentada uma proposta de elaboração do projeto cartográfico para a representação de postes e cabos de uma rede de distribuição de energia elétrica. Nero et al (2010) apresentam um exemplo de projeto desenvolvido, cuja ênfase está na modelagem da cartografia tridimensional para uso em SIG 3D.

É esperado que, por consequência, a representação tridimensional gerada a partir desta proposta possa auxiliar os técnicos da área de energia elétrica na identificação de problemas, na atualização da base de dados, no planejamento de novas obras bom como na leitura e proposição de padronização de símbolos para a representação dos elementos importantes.

Bol. Ciênc. Geod., sec. Artigos, Curitiba, v. 19, no 2, p.247-267, abr-jun, 2013. 


\section{FUNDAMENTAÇÂO TEÓRICA}

Os avanços tecnológicos das últimas décadas permitem aos cartógrafos criar uma grande variedade de produtos que podem ser vistos na tela do computador (PETROVIC, 2003), entre os quais os mapas 3D. Para a elaboração de mapas topográficos bidimensionais, os princípios cartográficos já estão bem estabelecidos, e são utilizados há décadas (HURNI e LEUZINGER, 1995, IMHOF, 1968; PESCADA e GRUENREICH, 1994) e mais recentemente, no Brasil, vale destacar a norma NBR 15777 (ABNT, 2009), a qual trata da padronização da simbologia para as escala 1:1.000 a 1:10.000. No entanto, existe pouco conhecimento consolidado para a geração de mapas tridimensionais (HAEBERLING, 1999). Mesmo os princípios para elaboração de mapas tridimensionais não estando bem definidos na Cartografia, alguns autores como Haeberling (2002; 2008), Petrovic (2003), Elmes (2005) e Bandrova (2005) realizaram pesquisas e testes para tentar estabelecer um projeto cartográfico para mapas tridimensionais.

As representações tridimensionais desde o início de seu uso foram elaboradas seguindo apenas técnicas de desenho animado e de animação de filmes e hoje seguem os padrões de desenhos computacionais, contrariando assim o processo de comunicação cartográfica. A eficiência dos mapas está diretamente ligada ao processo de comunicação cartográfica. Para que este processo ocorra de forma precisa é necessário que o cartógrafo projete mapas baseados na realidade do usuário. Kolácný (1969) apud Sluter (2008), o modelo de comunicação cartográfica, no qual o cartógrafo e usuário são dependentes um do outro a partir da sobreposição da realidade, como vista pelo cartógrafo, à realidade como entendida pelo usuário. As fases desse processo podem ser vistas na Figura 1.

Figura 1 - Versão do modelo de comunicação cartográfica de Koláčný (1969). Fonte: Sluter (2008).

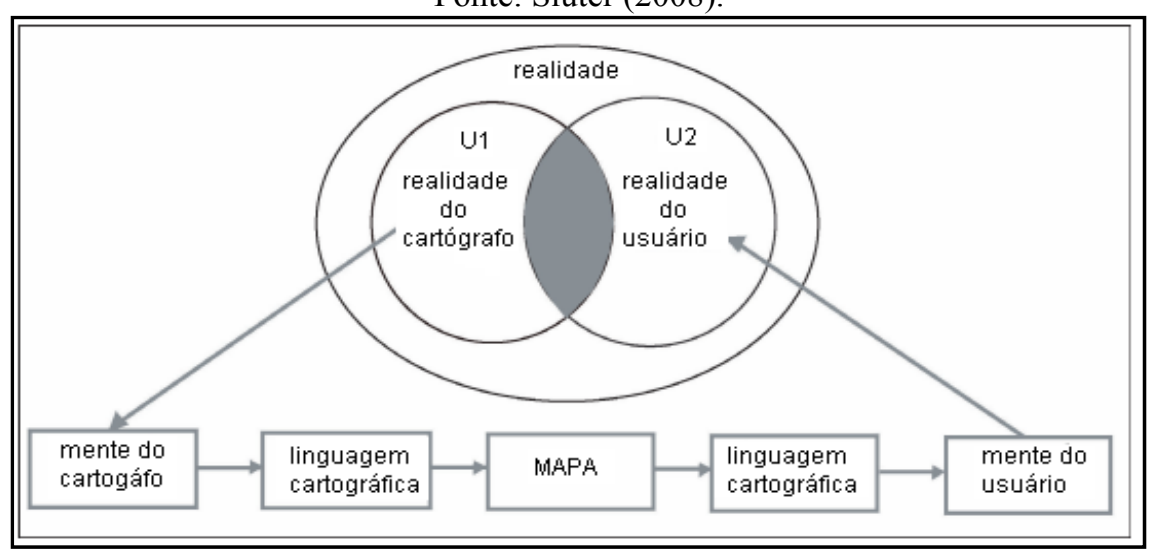


Os mapas tridimensionais por não serem elaborados seguindo princípios cartográficos apresentam problemas, principalmente, relacionados à simbologia, a qual se baseia em técnicas de desenho computadorizado e por tentarem reproduzir o mundo como ele é visto pelo usuário. Para um mapa cumprir seu papel de comunicação cartográfica o símbolo não pode ser altamente realista, pois se o símbolo é igual ao objeto representado, o modelo perde o significado já que o usuário não precisará interpretar as informações ali representadas (Yongjun, 2010). Haeberling (1999) apresenta alguns dos problemas encontrados na representação tridimensional ocasionados pela falta de princípios cartográficos, que são:

$>$ A não consideração das necessidades do usuário;

$>$ Elaboração de símbolos e legendas não adequadas para o tipo de uso e necessidades do usuário e;

$>$ A falta de princípios cartográficos para mapas tridimensionais.

A definição de princípios para elaboração de mapas tridimensionais aumentaria a coerência entre a criação e o significado dos símbolos do mapa. Os princípios cartográficos são necessários para definir a forma dos símbolos, para determinar o nível de detalhe da visualização em perspectiva e para determinar a posição geográfica dos elementos do mapa (HAEBERLING, 1999).

Elmes (2005) considera que existem três processos que são comuns a todos os mapas: a redução (que determina a escala), seleção e captação das informações e simbolização. Bandrova (2005) afirma que a criação dos mapas tridimensionais, realizada a partir de mapas em papel, necessita de oito etapas, mas quando os mapas tridimensionais são gerados a partir de arquivos de coordenadas em meio digital, são necessárias apenas seis etapas. Dentro desse contexto, Haeberling (1999, 2002, 2004, 2005, 2008) desenvolveu estudos para a elaboração de um projeto cartográfico para mapas tridimensionais. De acordo com estes estudos, o autor apresenta três aspectos que devem ser considerados (Figura 2).

A figura 2 corresponde aos três processos propostos por Heaberling (2004), a saber: a primeira fase é a modelagem de dados, que consiste em preparar e transformar os diferentes dados topográficos para torná-los compatíveis aos softwares que serão utilizados para geração dos mapas; a segunda fase é a simbolização, considerando a generalização cartográfica, que consiste na geração do modelo de paisagem, no qual as características gráficas de cada classe e atributos gráficos (forma, tamanho, cor, brilho, textura e outras características gráficas como nitidez e transparência) são adicionados aos objetos que compõem o modelo; a terceira fase consiste na visualização do modelo, a qual é a responsável pela compreensão e exibição do modelo cartográfico tridimensional na mídia designada e onde são determinados os demais parâmetros para a composição da apresentação da paisagem (iluminação e sombreamento). 
Figura 2 - Etapas para elaboração de um mapa 3D propostas por Terribilini (2001) e usadas por Haeberling (2002, 2004 e 2008).

Fonte: Haeberling (2004).

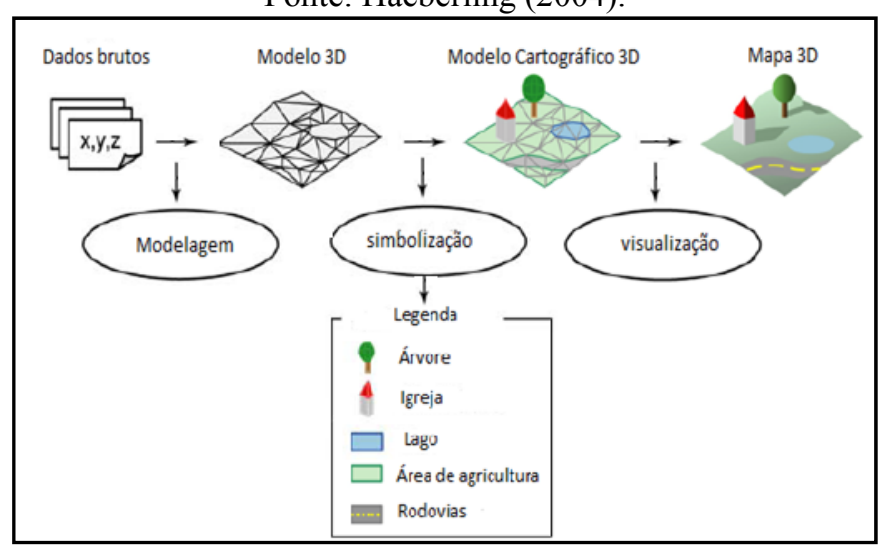

Para a elaboração do projeto cartográfico de mapas tridimensionais pode-se considerar as etapas do projeto cartográfico para mapas bidimensionais como referência, com as necessárias modificações em cada etapa, tendo em vista que os mapas tridimensionais, na sua grande maioria, são apresentados na tela do computador.

No projeto cartográfico de mapas tridimensionais apresentados por Haeberling (2004), as etapas são semelhantes às etapas realizadas nos mapas bidimensionais. Uma comparação entre as etapas de elaboração de mapas bidimensionais apresentados por Sluter (2008) com as etapas para elaboração de mapas tridimensionais apresentadas por Bandrova (2005) e Haeberling (2008) pode ser observada na Figura 3.

Na Figura 3 verifica-se que o projeto cartográfico apresentado por Haeberling (2008) é semelhante ao projeto cartográfico apresentado por Sluter (2008) para mapas bidimensionais. Apesar dos projetos desenvolvidos apresentarem uma ordem diferente de etapas, os propósitos das mesmas se equivalem.

A primeira etapa dos projetos de Sluter (2008) e Haeberling (2008) é a identificação do usuário e suas necessidades e Bandrova (2005) não realiza esta etapa; a segunda etapa do projeto de Sluter (2008) é a definição de cada mapa a ser projetado, enquanto que na proposta de Haeberling (2008) a definição dos mapas a serem projetados faz parte da última etapa, a definição do produto, e Bandrova (2005) não desenvolve esta etapa. Essa diferença de ordens das etapas realizadas por Sluter (2005) e Haeberling (2008) acontece porque nos mapas bidimensionais a definição de cada mapa a ser projetado está diretamente ligada às necessidades do usuário e a sua forma de entendê-lo. Nos mapas tridimensionais, a falta de conhecimento de que tipo de informação o usuário busca com o uso do mapa faz 
com que o seu produtor dê mais importância a sua aparência. Com isso, a escolha dos mapas a serem projetados ocorre na última etapa no projeto de Haeberling (2008). A etapa três do projeto de Sluter (2008) não é desenvolvida por Haeberling (2008) e por Bandrova (2005), tendo em vista que estes autores desenvolvem modelos tridimensionais, nos quais a escala não é estática e sim interativa, diferente dos mapas bidimensionais. A quarta etapa do projeto de Sluter (2008) corresponde, respectivamente à primeira e segunda etapa de Bandrova (2005) e Haeberling (2008); a sexta etapa do projeto cartográfico de Sluter (2008) corresponde à segunda e terceira etapa de Bandrova (2005) e Haeberling (2008), respectivamente.

Figura 3 - Comparativo das etapas de projeto cartográfico para mapas bidimensionais e mapas tridimensionais a partir dos conceitos de Sluter (2008),

Bandrova (2005) e Haeberling (2008).

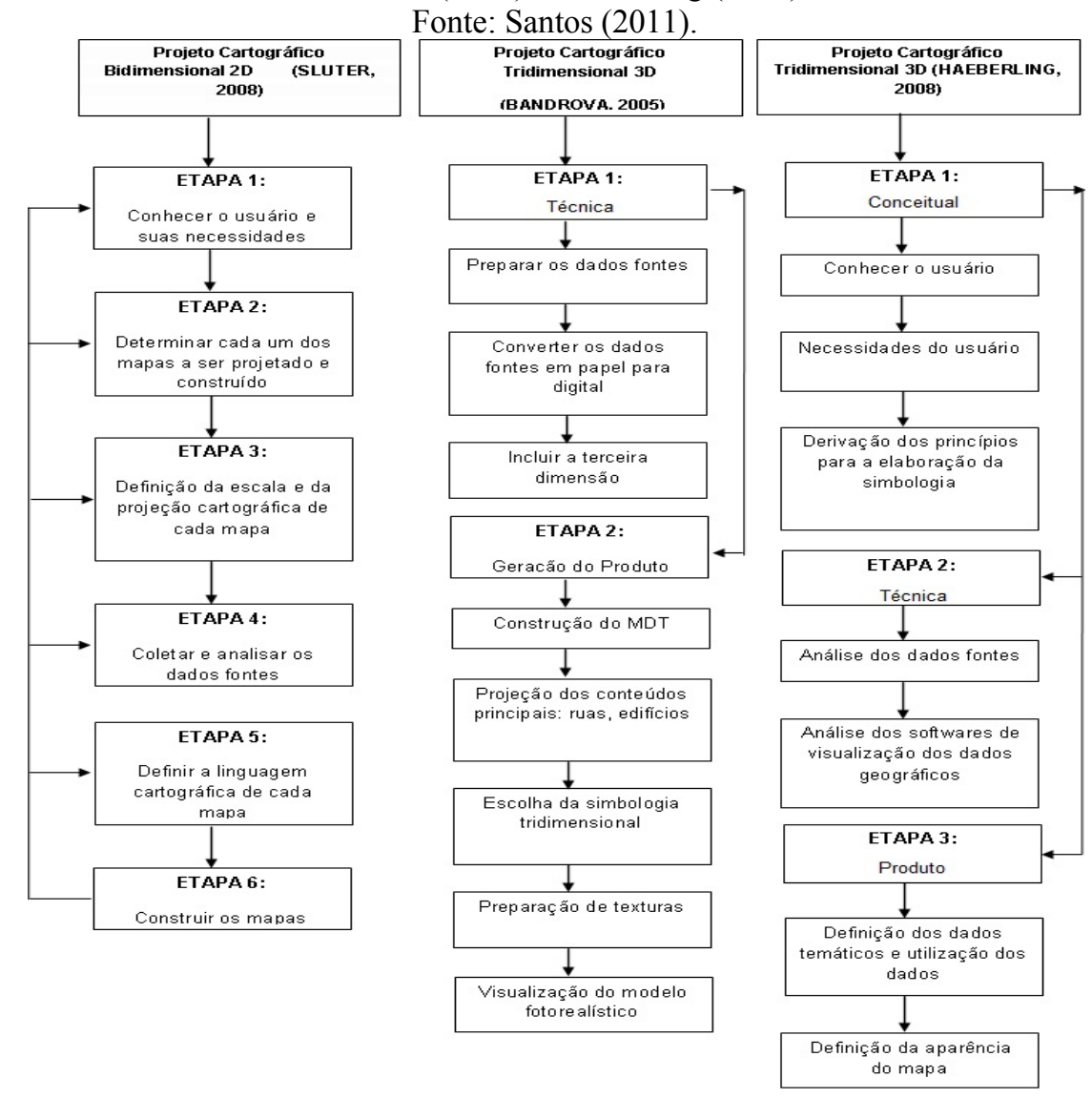

Bol. Ciênc. Geod., sec. Artigos, Curitiba, v. 19, no 2, p.247-267, abr-jun, 2013. 
Para Sluter (2008), nos mapas bidimensionais a escolha da simbologia é definida na quinta etapa (pois essa simbologia está implícita na linguagem). Isso por que a relação entre projeto cartográfico e comunicação cartográfica não ocorre apenas pela definição da simbologia de cada mapa, mas também pelo uso dos mesmos. Como cada mapa deve ser construído para atender as necessidades de cada usuário, para cada mapa específico é definida uma linguagem cartográfica, que inclui a simbologia.

A elaboração dos símbolos bidimensionais deve considerar três aspectos interdependentes: a dimensão espacial da feição (ponto, linha ou área) e a primitiva gráfica para representá-la; o nível (ou escala) de medida, definido pelas características do fenômeno a ser representado; e as variações visuais (variáveis visuais) das primitivas gráficas, que serão usadas para representar as feições e suas classificações. Nos mapas tridimensionais a definição da simbologia faz parte da primeira fase do projeto cartográfico; isso porque Haeberling (1999) acredita que nos mapas tridimensionais a simbologia deve ser completamente voltada para o usuário e suas necessidades, e essas necessidades têm uma forte influência na aparência gráfica dos mapas tridimensionais.

A última etapa responsável pela geração e visualização dos mapas ocorre para os três projetos cartográficos na mesma ordem, ou seja, ao final após os mapas terem sido projetados.

No projeto cartográfico apresentado por Bandrova (2005) são desenvolvidas apenas duas etapas: a etapa técnica (que trata dos dados fontes, sejam analógicos ou digitais) e a geração do produto (que trata da projeção das feições reais, escolha da simbologia, preparação de texturas e a visualização). O projeto desenvolvido por Bandrova (2005) não apresenta o contexto do usuário com suas necessidades como mostrado por Haeberling (2008), porque sua representação é altamente realística, o que coloca a escolha da simbologia em segundo plano. Bandrova (2005) e Haeberling (2008) desenvolveram projetos cartográficos para representação tridimensionais, sendo que Haeberling (2008) tem como produto final um mapa tridimensional, enquanto que Bandrova (2005) apresenta como produto final uma representação altamente realística, perdendo assim o significado de mapa.

\section{DEFINIÇÃO DA PROPOSTA DE PROJETO CARTOGRÁFICO PARA REPRESENTAÇÃO TRIDIMENSIONAL DE REDES DE DISTRIBUIÇÃO DE ENERGIA ELÉTRICA}

Para a elaboração do projeto cartográfico tridimensional para redes de distribuição de energia elétrica consideraram-se como base as etapas para elaboração de mapas bidimensionais descritas por Sluter (2008) e para mapas tridimensionais descritas por Haeberling (2008). As alterações consideradas nesta pesquisa referem-se às etapas de escolha da simbologia e da escala de representação. As etapas descritas por Bandrova (2005) não foram consideradas neste trabalho porque seu projeto é para a elaboração de uma representação 
altamente realística, que não é o foco deste trabalho. As etapas da metodologia empregada nesta pesquisa podem ser observadas na Figura 4.

Figura 4 - Fluxograma das etapas do projeto cartográfico para desenvolvimento dessa pesquisa.

Fonte: Santos (2011).

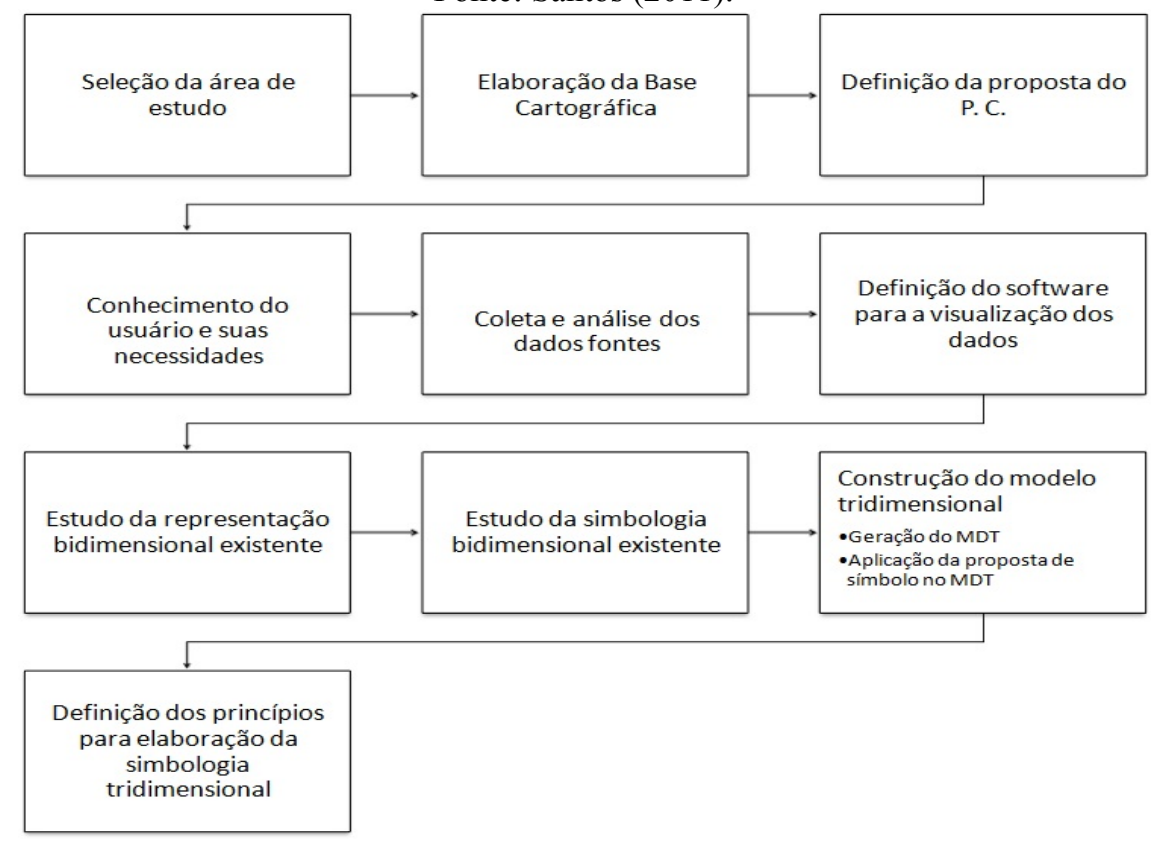

\subsection{Conhecimento do usuário e suas necessidades}

A primeira tarefa realizada no projeto cartográfico consiste em conhecer o usuário e suas necessidades. Para esta pesquisa o usuário escolhido foi a empresa COPEL (Companhia Paranaense de Energia Elétrica), em virtude dos seus dados tridimensionais estarem sobre a superfície, o que possibilitou pesquisas e análises em campo. A COPEL é responsável pela geração, transmissão e distribuição de energia elétrica, além do cadastro e da manutenção das redes de distribuição. Com o usuário e suas necessidades estabelecidas foi escolhida a área de estudo, localizada na zona urbana da cidade de Curitiba, Estado do Paraná. O Bairro Jardim das Américas foi escolhido por apresentar informações significativas dos elementos de estudo dessa pesquisa (os postes e cabos da rede de energia elétrica), além da acessibilidade para pesquisa em campo para coleta de informações. A figura 5 ilustra a área de estudo no Município de Curitiba. 
Figura 5 - Localização da área de estudo em escala de visualização aproximada de $1: 280.000$ e $1: 28.000$.

Fonte: Santos (2011).

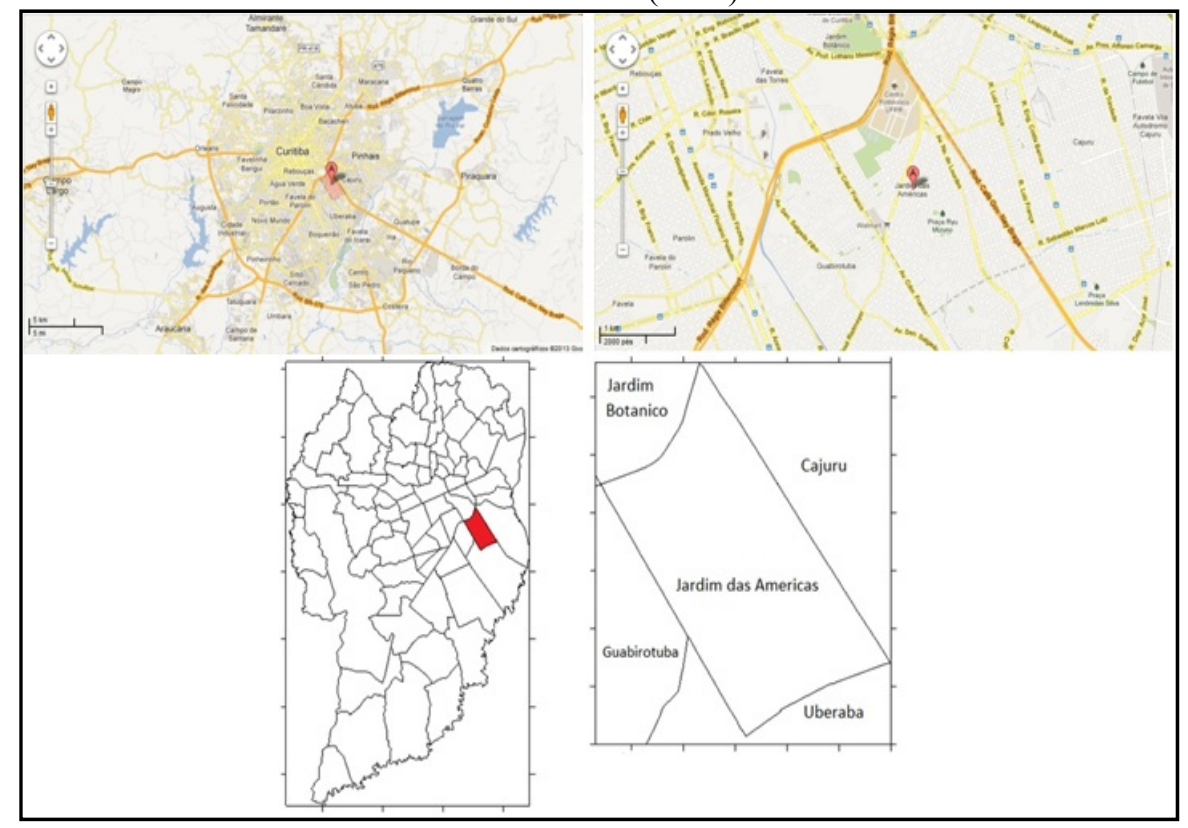

\subsection{Modelagem da base cartográfica e criação do modelo tridimensional}

A modelagem foi aplicada à base cartográfica da área de estudo na escala 1:3.000, proveniente de restituição fotogramétrica de fotografias aéreas fornecidas em meio digital pelo Instituto de Pesquisa e Planejamento Urbano de Curitiba IPPUC, na escala 1:12.000. As ortofotos foram fornecidas em formato TIF, na escala 1:3.000, tendo como sistema de referência o Datum horizontal SAD-69 Curitiba. Para a composição da base os dados da rede de distribuição de energia elétrica foram necessários. Esses dados foram fornecidos pela Companhia Paranaense de Energia (COPEL), em formato SHP (shapefile), no sistema de referência SAD-69, projeção cartográfica UTM e na escala 1:2.000.

As feições fornecidas pela COPEL foram: chaves, iluminação pública, postes, quadras, rede primária e secundária e transformadores. Os dados referentes aos postes foram fornecidos pela COPEL em uma única tabela e por isso foram classificados por tipo de poste, de forma manual, no software ArcGIS. Os dados das redes primárias e secundárias foram editados também de forma manual por conterem linhas sobrepostas e duplicação de informação. 
Para a geração do modelo tridimensional foi escolhido o software ArcGIS 9.3, e para a visualização do cenário tridimensional o software ArcScene 9.3. No ArcGIS 9.3 o modelo digital do terreno foi gerado a partir de dados laser scanner aerotransportado e curvas de nível com eqüidistância de 5 em 5 metros. Os dados laser, coletados em 2010, foram fornecidos pela empresa ESTEIO Engenharia e Aerolevantamentos S.A., e encontram-se no formato XYZ e no sistema de referência UTM/SAD-69. As curvas de nível são do ano de 1999 e foram fornecidas pelo IPPUC no formato SHP no sistema de referência SAD-69. Como os dados laser cobriam apenas parte da área de estudo, foi necessário o uso de curvas de nível para complementar as informações altimétricas da região.

\subsection{Descrição da representação bidimensional do sistema de redes de energia elétrica realizada pela COPEL}

A COPEL faz a representação das suas redes através do Webgeo, sistema desenvolvido para uso exclusivo da mesma, usado para acessar os dados correspondentes à cartografia, cadastro da rede elétrica, projetos elétricos e imagens na internet. O sistema foi desenvolvido em linguagem Java e JSP e sua criação foi baseada no ArcGIS Server da ESRI.

A representação bidimensional das redes de energia elétrica gerada pela concessionária é utilizada para manutenção da rede e identificação de possíveis problemas de funcionamento em equipamentos que compõem a rede de transmissão de energia elétrica.

A simbologia dos elementos contidos na rede de distribuição de energia elétrica é realizada pela COPEL com base na classificação em classes e subclasses das feições cartográficas de interesse. A partir de consultas à norma técnica da COPEL de $n^{\circ} 841.005$ referente ao desenho de redes de distribuição, pode-se identificar quinze classes diferentes de elementos: postes, condutores, transformadores, chaves, pára-raios, reguladores, banco de capacitores, comando de iluminação com relé fotoelétrico, luminárias, caixa de derivação, estais, ligações à terra, ligações em cruzamento aéreo, ancoragem e estais com postes.

Para o desenvolvimento desta pesquisa foi selecionada a classe postes, que apresenta várias subclasses definidas em função do tipo de material, da forma, da altura e da voltagem.

De acordo com a norma técnica analisada os postes representados na seção duplo T ainda podem se subdividir em 24 tipos, classificados por voltagem e altura. Os postes de seção circular estão subdivididos em 15 tipos, também classificados por voltagem e altura. Os postes de seção quadrada estão classificados em três tipos em função apenas da altura.

\subsection{Definição dos princípios para elaboração da simbologia tridimensional}

Uma etapa importante no projeto cartográfico é a elaboração da simbologia já que essa é responsável pela interpretação das informações representadas e torna possível que o usuário adquira novos conhecimentos com as informações 
representadas no mapa. Com isso neste trabalho foi elaborada uma proposta de símbolos tridimensionais para a classe poste; porém sugeriu-se também uma proposta de símbolos para a representação dos cabos da rede elétrica para complementar a visualização tridimensional.

Nesta fase foi importante considerar os princípios de elaboração da simbologia descritos por Haeberling (1999), que afirma que para elaboração de símbolos tridimensionais, além de respeitar os conhecimentos do usuário e tipo de uso desses mapas, deve-se considerar também a aparência gráfica do mapa, os parâmetros de vista da cena e a interatividade do modelo, no nível de detalhe do símbolo e no zoom. Com isso a elaboração da proposta de símbolos foi realizada seguindo os princípios do projeto cartográfico para representações bidimensionais adequando-as à representação tridimensional. Na elaboração dos símbolos foi considerada a sugestão dos usuários sobre o uso dos símbolos. Os técnicos da COPEL se dividiram em dois grupos sendo que um deles preferiu os símbolos tridimensionais realísticos, o que seria mais atraente por se tratar de um modelo tridimensional. E o outro grupo de usuários sugeriu a produção tridimensional dos símbolos da norma técnica, já que os técnicos estão familiarizados com a simbologia. Com isso, esta fase foi dividida em duas etapas: a elaboração de símbolos realísticos simplificados e a elaboração de símbolos geométricos.

Para a elaboração destes símbolos foi necessário pesquisar, em campo, a forma dos postes (registrada por meio de fotografias) a fim de extrair os modelos finais para estes símbolos.

Os símbolos realísticos foram gerados no software AutoCAD 2010, utilizando a função 3D. Os símbolos foram exportados no formato DWG para o AutoCAD 2006 para então serem transformados para o formato 3DS e posterior exportação para o software SketchUp para adição da textura. Com a textura adicionada e transformada no formato COLLADA foi feita a exportação para a biblioteca de símbolos do ArcGIS.

A segunda fase da elaboração dos símbolos compreendeu a criação de símbolos geométricos tridimensionais, gerados a partir de consultas à norma técnica da COPEL de $n^{\circ} 841005$ referente ao desenho de redes de distribuição de energia elétrica. Os símbolos geométricos foram elaborados no AutoCAD 2010, exportados no formato DWG para o AutoCAD $2006 \mathrm{e}$, em seguida transformados para o formato 3DS e exportados para a biblioteca de símbolos do ArcGIS. Os símbolos geométricos elaborados nessa fase são os constantes da referida norma técnica, apenas em formato tridimensional. A Figura 6 apresenta os símbolos bidimensionais da norma técnica. 
Figura 6 - Símbolos bidimensionais usados pela COPEL

Fonte: COPEL (2003).

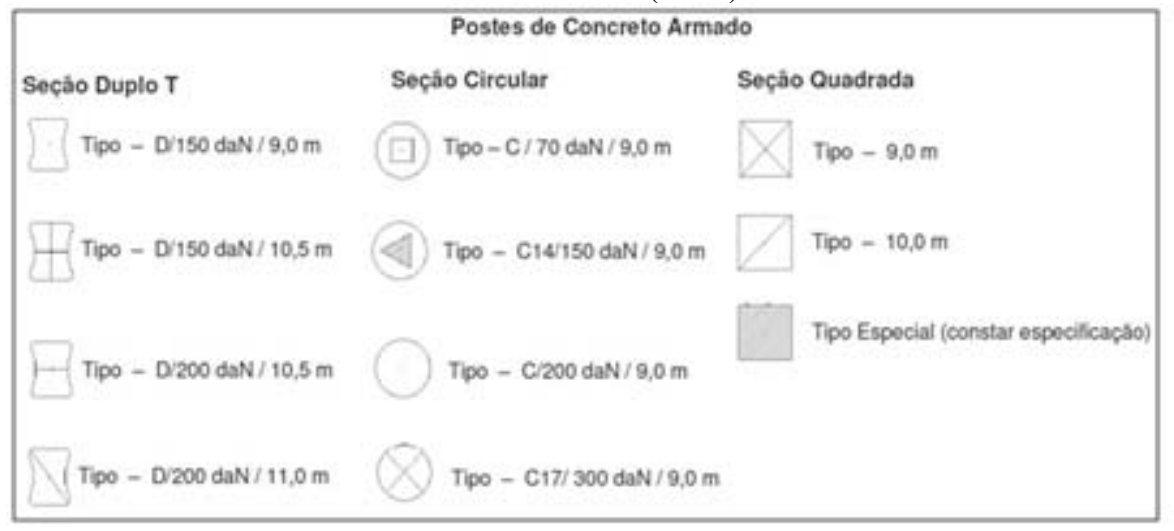

\section{RESULTADOS E DISCUSSÃO}

\subsection{Descrição das necessidades do usuário}

A partir da identificação do usuário e de pesquisas realizadas para entender quais as suas principais necessidades pode-se verificar que estão relacionadas à visualização da rede e seus elementos. Existem também necessidades técnicas, relacionadas ao atendimento das exigências da ANEEL (Agência Nacional de Energia Elétrica) e ao controle dos elementos que compõem a rede, tais, como chaves e transformadores.

Entretanto, as necessidades de visualização da rede e seus elementos consistem na principal necessidade e também preocupação da COPEL, isso porque a concessionária almeja com essa visualização a identificação de áreas de riscos com construções irregulares, consumidores ligados à rede de forma ilegal e não segura, redes fora dos padrões de altura mínima necessária para a segurança do consumidor, além das necessidades de manutenção.

\subsection{Descrição da representação bidimensional utilizada pela COPEL}

A partir de observações e discussões sobre a atual representação da rede de distribuição de energia elétrica usada pela COPEL foi possível detectar alguns problemas do ponto de vista da representação cartográfica.

Tais problemas referem-se às redes de distribuição de energia elétrica, que são trifásicas, mas têm a sua representação feita de forma unifilar (Figura 7). Esse tipo de representação só ocorre de forma teórica, pois para representar uma rede trifásica em mapas bidimensionais, sem torná-la confusa e sem a sobreposição de todos os seus elementos, é necessário adotar um processo de representação diferenciado. Assim, para que os técnicos possam visualizar e identificar os elementos da rede, a 
COPEL representa um dos cabos com a sua localização geográfica verdadeira. $\mathrm{O}$ segundo cabo é representado com um deslocamento de mais ou menos um metro da sua verdadeira localização, ou seja, o cabo não pode ser visualizado sob condições reais, enquanto o terceiro cabo simplesmente não é representado, resultando num elemento oculto para a representação. O problema se agrava quando à rede são incorporadas as quadras, pois os cabos têm que ser deslocados para que não se sobreponham às mesmas. A sobreposição de informação torna difícil a leitura e interpretação dos elementos mapeados.

Figura 7 - Representação bidimensional usada pela COPEL nas escalas a) 1:1.000, b) 1:2.000 e c) 1:500.

Fonte: Santos (2011).

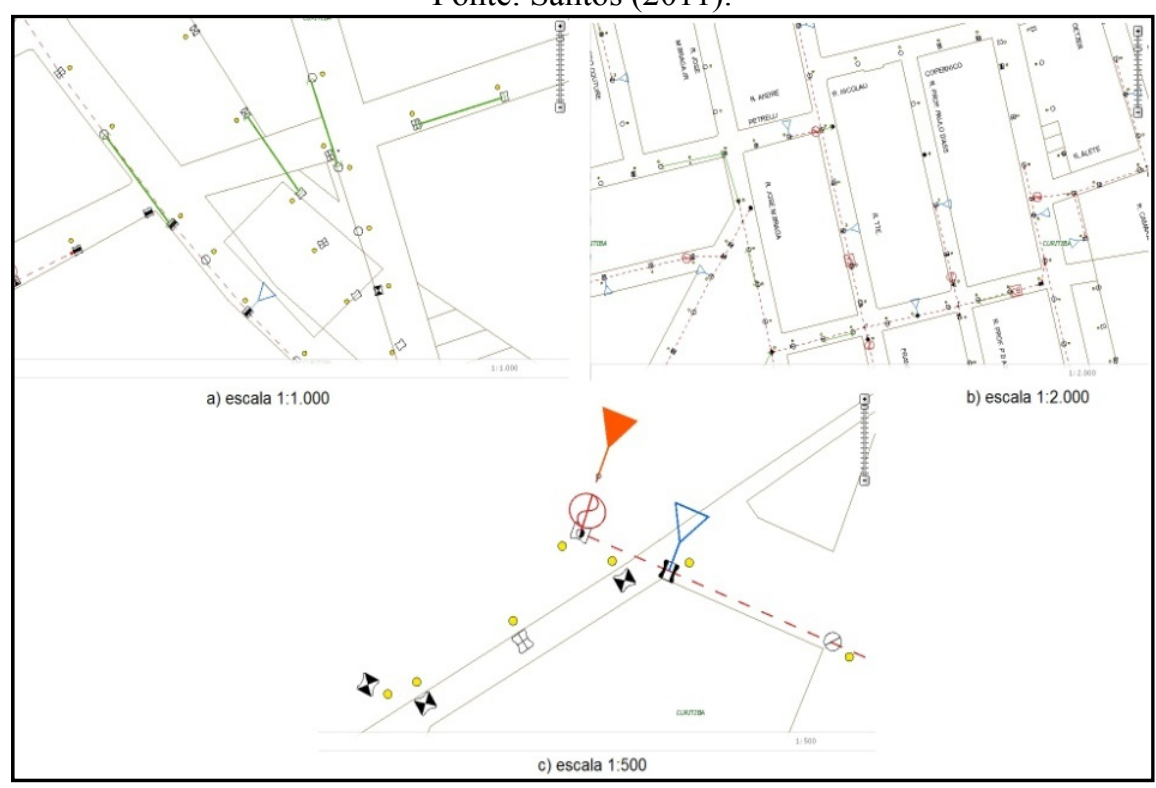

Em relação à simbologia usada pela COPEL os símbolos são geométricos. Esses símbolos apresentam uma forma regular, não possuem significado direto, mas são fáceis de desenhar. Por terem formas simples, não ocupam muito espaço nas representações e, com isso, diminuem a possibilidade de oclusão de outros detalhes presentes nos mapas (BOS, 1984). Um problema encontrado no uso de símbolos geométricos é que nenhum significado explícito está associado a este tipo de representação. Para que os símbolos possam ser reconhecidos deve-se sempre recorrer à legenda. Por outro lado, a utilização de uma simbologia que é de conhecimento prévio do usuário e de seu uso diário, facilita a interpretação da simbologia tridimensional proposta por parte destes. 
Os símbolos bidimensionais são diferenciados uns dos outros a partir do uso das variáveis visuais: forma, orientação e textura. A forma é usada para diferenciar os postes por tipo de material, inclusive das suas subclasses (seção duploT, circular, quadrada e de trilho). A orientação e a textura são usadas de forma combinada para diferenciar as subdivisões em alturas e voltagens. As diferentes classes de postes, subclasses e respectivas divisões, além dos símbolos e das variáveis visuais usadas pela COPEL podem ser observadas na Figura 8.

Figura 8 - Símbolos bidimensionais usados pela COPEL

Fonte: Santos (2011).

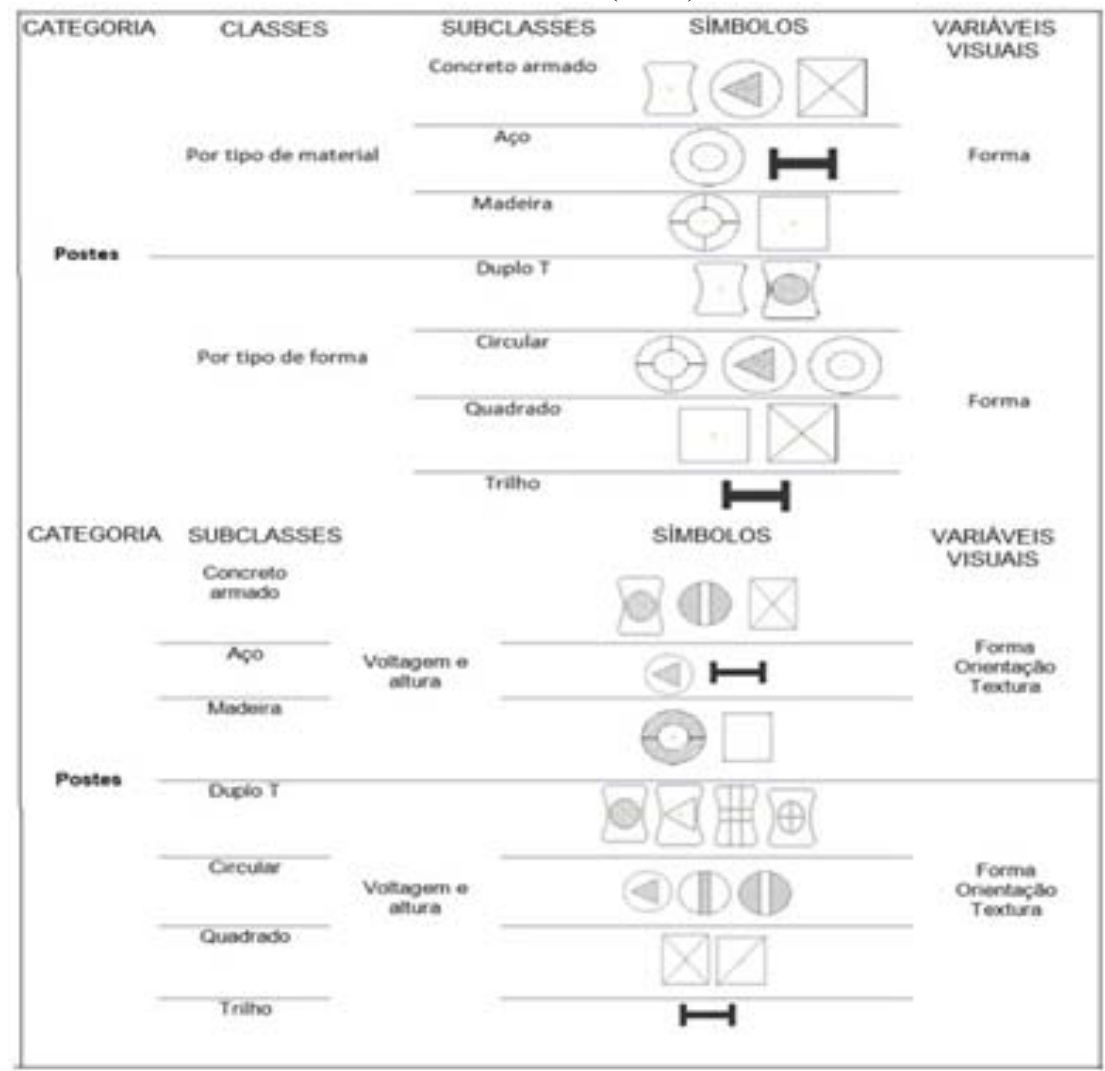

\subsection{Projeto dos símbolos tridimensionais}

Neste item é apresentado o projeto da proposta da simbologia para a representação dos postes das redes de energia elétrica, que foi dividido em duas 
etapas, sendo a primeira para os símbolos realísticos simplificados e a segunda para os símbolos geométricos.

Os símbolos foram criados no software AutoCAD 2006 com as dimensões iguais às encontradas no campo e foram elaborados em três alturas distintas: $9 \mathrm{~m}$, $10 \mathrm{~m}, 12 \mathrm{~m}$, já que o software AutoCAD permite a elaboração de objetos em tamanhos reais como os encontrados no campo; mesmo que a espessura dos postes varie de acordo com a sua altura optou-se em manter a espessura fixa de $30 \mathrm{~cm}$ para as três variações de altura. Esses símbolos, quando exportados para biblioteca de símbolos do ArcGIS, têm suas dimensões reais mantidas, enquanto na fase de visualização do modelo essas dimensões variam de acordo com a escala de visualização dos dados.

Para a elaboração dos símbolos realísticos foi realizada uma pesquisa em campo, sendo realizadas tomadas fotográficas, para extrair os modelos reais dos postes (Figura 9). Como resultado foram detectados três subclasses diferentes: forma, materiais e voltagem. A subclasse forma se subdivide em três: circular, quadrado e duplo T. A subclasse materiais também se subdivide em três: aço, concreto e madeira; e a subclasse voltagem que, no mundo real, é evidenciada pela diferença de altura e espessura dos postes. Quanto maior a voltagem, maior a altura e espessura do poste.

Ao fim dessa etapa foram gerados dois tipos de postes: circular e duplo T, já que o quadrado não foi encontrado na área de estudo e o tipo trilho não existe mais na área urbana da cidade de Curitiba. As variações das classes e subclasses encontradas na classe postes foram realizadas usando variáveis visuais: textura e altura e a espessura do poste se manteve fixa nesta proposta (Figura 9). Os símbolos realísticos foram elaborados porque os usuários de modelos tridimensionais esperam que a simbologia utilizada seja semelhante aos objetos do mundo real.

Para a elaboração dos símbolos geométricos foi realizada uma análise na norma técnica usada pela COPEL para extrair os modelos de símbolos em uso. Com base neste documento foram propostos quatro tipos de símbolos com variações em forma: circulares, quadrados, trilho, duplo $\mathrm{T}$.

Os símbolos, além de variarem em forma também sofrem variação em textura e orientação. O símbolo usado para representar o poste duplo T, apesar de manter a mesma forma, apresenta 24 variações em voltagem e altura, representadas por diferentes texturas que variam em orientação. Para o símbolo circular, que representa o poste circular, ocorre o mesmo, uma variação de 21 tipos de símbolos circulares diferenciados pela textura e orientação para representar as diferentes voltagens. O símbolo quadrado usado para representar o poste quadrado sofre uma variação de 3 tipos diferentes de altura. O símbolo usado para representar o poste tipo trilho não sofre variação. A variação por tipo de material foi realizada usando texturas diferentes para cada tipo de material. Os símbolos geométricos tridimensionais foram gerados de forma que seguissem o mesmo padrão dos símbolos bidimensionais. O símbolo bidimensional foi totalmente reproduzido no topo do símbolo tridimensional (Figura 10). 
Figura 9 - Comparativo entre a feição real e os símbolos propostos.

Fonte: Santos (2011).

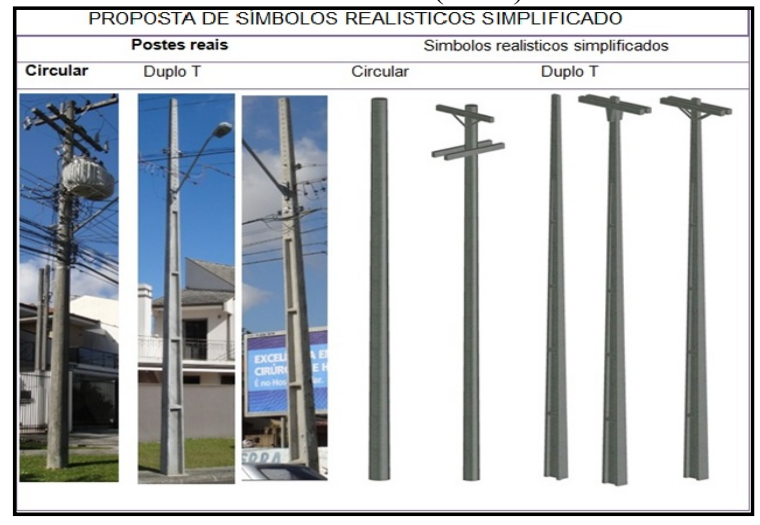

A elaboração dos símbolos geométricos foi realizada porque os usuários dessa pesquisa já estão habituados a trabalhar com esses símbolos, o que facilita sua identificação no modelo tridimensional.

As redes elétricas são compostas por quatro cabos, que são: três fases $\mathrm{A}, \mathrm{B}$, e $\mathrm{C}$ e um neutro. Para a representação desses cabos nos modelos tridimensionais será adotado um símbolo linear, preservando a característica da feição original, tendo como variação gráfica tom de cor. Isso porque, segundo Keates (1973), a variação em cor é o aspecto mais abrangente da variação de um símbolo, principalmente porque existe uma grande variedade de diferenças visuais provocadas pela cor e os símbolos lineares são dependentes da variação em tom de cor (Figura 11).

Figura 10 - Comparativo entre os símbolos bidimensionais e os símbolos geométricos tridimensionais.

Fonte: Santos (2011).

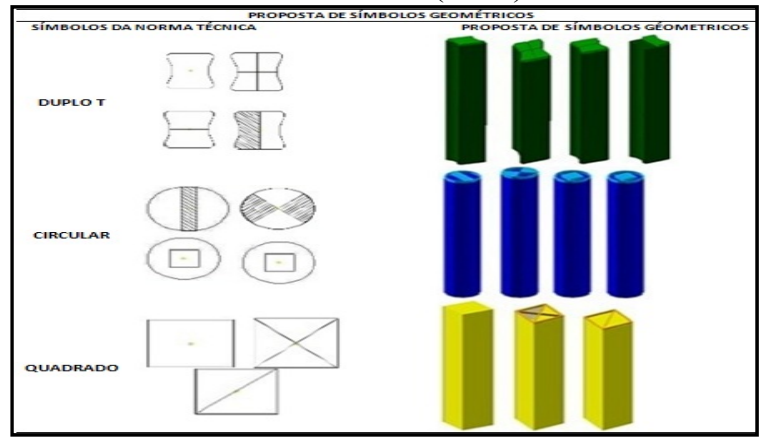

Bol. Ciênc. Geod., sec. Artigos, Curitiba, v. 19, no 2, p.247-267, abr-jun, 2013. 
Figura 11 - Comparativo entre os símbolos bidimensionais e os símbolos tridimensionais para a feição cabos.

Fonte: Santos (2011).

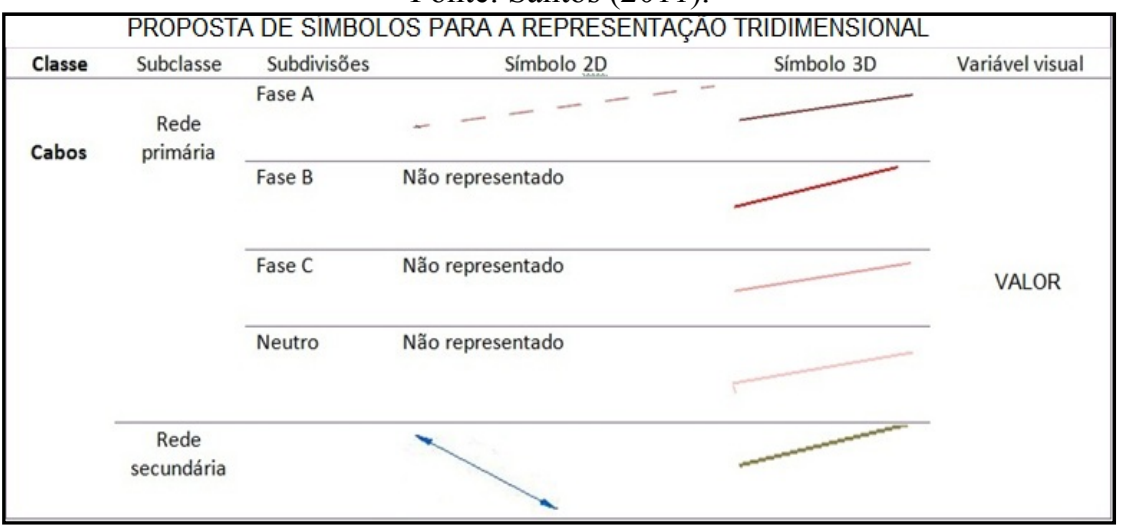

Para a composição da representação tridimensional das redes foi gerado um MDE no ArcGis 9.3, visto que esse software abrange as necessidades de tridimensionalidade exigidos. Os dados usados como base para a elaboração do modelo digital de elevação (MDE) consistiram de curvas de nível e dados laser scanner. A partir das curvas de nível realizou-se uma transformação das curvas de nível em uma nuvem de pontos cotados, que foram compatibilizados com os dados laser scaner para a geração do modelo tridimensional. Este foi gerado utilizando a estrutura TIN. A visualização do modelo tridimensional foi realizada no ArcScene. O MDE foi gerado com uma resolução de pixel de $10 \mathrm{~m}$ e tendo como sistema de referência o SAD 69, Fuso 22S e projeção cartográfica UTM. Após a geração do modelo tridimensional do terreno, os símbolos foram adicionados ao modelo.

\subsection{Aplicação da Proposta de Símbolo do Modelo Tridimensional}

A primeira etapa da proposta de simbologia compreendeu a elaboração de símbolos realísticos simplificados para representar os postes. Com estes símbolos representados no modelo, pode-se concluir que os mesmos não são os mais adequados para a representação dos postes, pois estes elementos possuem muitos detalhes e características que, de acordo com a escala de visualização, não são passíveis de identificação (Figura 12). A representação de tais elementos exigiu um esforço computacional grande. Para Petrovic (2001), nas representações tridimensionais o uso de um símbolo geométrico ocuparia menos espaço de memória computacional do que um símbolo tridimensional realístico.

Como a COPEL visualiza os seus dados em várias escalas, haveria a necessidade de criar um símbolo para cada escala, já que nos modelos tridimensionais a mudança de escala não ocorre de forma linear (PETROVIC, 2003). As representações realísticas, apesar de apresentarem uma forte ligação com 
a realidade, nem sempre são a forma mais adequada de representar os fenômenos geográficos. Caso se queira que a apresentação tridimensional mantenha sua função de comunicação cartográfica como nos mapas bidimensionais, deve ser incluído um sistema de simbologia (PETROVIC, 2001).

A segunda etapa da proposta de simbologia compreendeu a elaboração de símbolos geométricos baseados na norma técnica da COPEL. À vista dos resultados práticos, ou sejam com estes símbolos representados no modelo, pode-se concluir visualmente que os símbolos geométricos são os mais adequados para a representação dos postes (Figura 13).

Esse resultado é justificado porque, segundo Kaetes (1973), além de identificar e discriminar os símbolos, também é possível realizar o reconhecimento dos símbolos representados. A facilidade na identificação desses símbolos é causada pela familiaridade que o usuário tem com o objeto representado. $\mathrm{O}$ usuário quando reconhece um símbolo classifica ou o associa com outros elementos conhecidos, ou o relaciona com imagens da sua memória e experiências vividas, dependendo do seu conhecimento prévio do símbolo. Esse conhecimento prévio ou familiaridade com o símbolo depende do usuário, da sua experiência e não do estimulo proporcionado pelo símbolo. Então, Keates (1973) acredita que, por mais que o usuário tenha prática com mapas, ele vai preferir os símbolos que lhe são familiares.

Figura 12 - Representação realística da rede com escala aproximada de 1:500. Fonte: Santos (2011).

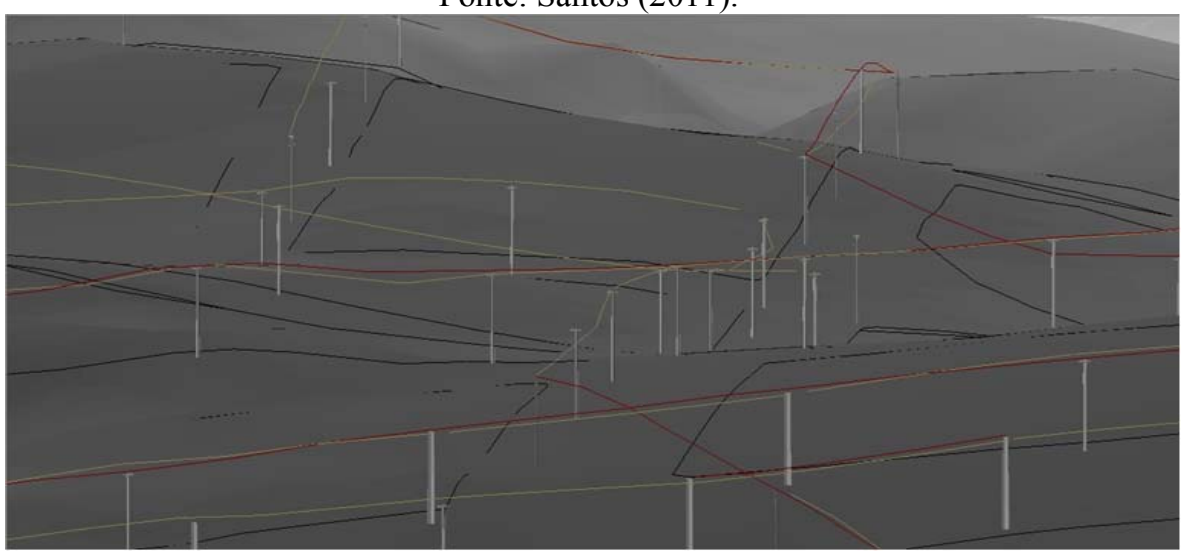

Como os técnicos da COPEL trabalham há alguns anos com símbolos geométricos e não fazem uso de legenda em suas representações, justifica-se o uso dos símbolos geométricos presentes na norma para a representação tridimensional, facilitando assim o processo de comunicação cartográfica, uma vez que o esforço mental para reconhecer os símbolos será mínimo. 
Figura 13 - Representação geométrica da rede na escala aproximada de 1:500. Fonte: Santos (2011).

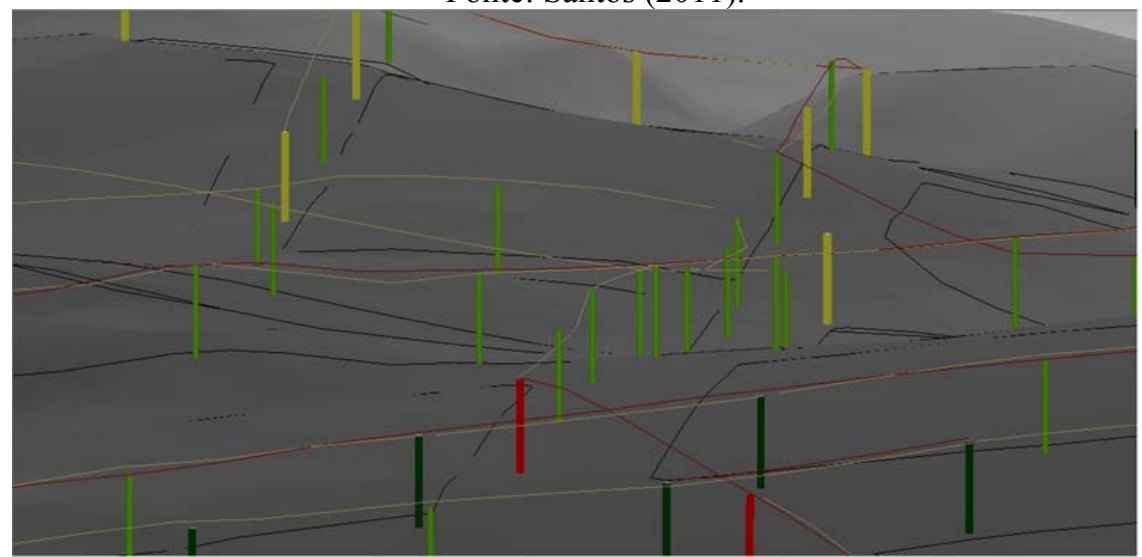

\section{CONCLUSÕES}

O desenvolvimento deste trabalho teve como objetivo propor um projeto cartográfico para representação tridimensional do sistema de distribuição de energia elétrica, tendo em vista que tais representações têm sido geradas sem considerar os princípios cartográficos, seguindo apenas as preferências dos cartógrafos ou outros profissionais envolvidos nesta função.

A proposta do projeto cartográfico foi realizada seguindo os princípios de elaboração para mapas bidimensionais, já estabelecidos há décadas, com as devidas adequações para as etapas de escolha de escala e elaboração dos símbolos, sendo que as mudanças foram baseadas em pesquisas realizadas por outros autores citados nesse artigo.

A elaboração da simbologia nos mapas tridimensionais deve seguir princípios cartográficos, assim como ocorre nos mapas bidimensionais, a fim de que se cumpra o processo de comunicação cartográfica. Em relação a este artigo, a representação cartográfica foi gerada a fim de atender as necessidades dos técnicos da concessionária de energia elétrica do Paraná, a COPEL, para a qual a proposta de simbologia foi desenvolvida por meio das primitivas gráficas e com variações feitas através das variáveis visuais.

Dentro da proposta de símbolos, os que se mostraram mais adequados para a representação da feição poste, foram os símbolos geométricos, tendo em vista a ampla experiência dos usuários com esses símbolos, os mesmos são mais fáceis de modelar e a transição de escalas torna-se mais fácil.

Atualmente as pesquisas nesta área encontram-se num estado inicial, aumentando assim as dificuldades em estabelecer critérios sólidos para representar o mundo como ele realmente é visto pelo usuário. Os resultados dessa pesquisa são 
parciais, tendo em vista que não foram realizados testes com os usuários para analisar a eficiência e eficácia dos símbolos propostos.

Uma dificuldade encontrada para a realização dessa pesquisa é a escassez de bibliografia específica, tanto no que diz respeito à elaboração da simbologia e do projeto cartográfico como no emprego das variáveis visuais.

Assim, recomenda-se a elaboração de testes de percepção visual para avaliar se a simbologia proposta é eficiente e/ou eficaz. Recomenda-se também que esses testes sejam realizados com os técnicos da COPEL para que se possa validar a simbologia.

Recomenda-se ainda que sejam realizados estudos mais aprofundados sobre o projeto cartográfico para mapas tridimensionais com o intuito de estabelecer princípios para a elaboração destes produtos da mesma forma que existem princípios estabelecidos para os mapas bidimensionais. Recomenda-se a visualização da representação bidimensional em conjunto com a representação tridimensional, para que se possa avaliar qual representação atende as necessidades do usuário.

\section{AGRADECIMENTOS}

As autoras agradecem à CAPES pelo suporte aos estudos da primeira autora $\mathrm{e}$ ao CNPq pelo apoio à pesquisa. Também agradecem a COPEL, IPPUC e ESTEIO pelo acesso aos dados e informações utilizadas.

\section{REFERÊNCIAS BIBLIOGRÁFICAS}

BANDROVA, T. Designing of symbol system for 3D city maps. 2001.

BANDROVA, T. Innovative Technology for the Creation of 3d Maps. Data Science Journal, 4 (2005) 53.

BOS, E. S. Cartographic Symbol Design. The Netherlands: ITC, 1984a. Cartographic Conference, 21. 2003, Durban: ICC, 2003. p.1920-1926.

HAEBERLING C. Cartographic Design Principles for 3d Maps - A Contribution to Cartographic Theory. In: INTERNATIONAL CONFERENCE CARTOGRAPHY, 21.,2005, La Corunã. Proceedings. La Corunã: ICC-ICA, 2005.

HAEBERLING, C. A Systematic of Important Graphic Aspects. In: ICA MOUNTAIN CARTOGRAPHY WORKSHOP, 2002, Oregon. Proceedings Oregon: ICC-ICA, 2002.

HAEBERLING, C. Symbolization in Topographic 3D-Maps: Conceptual Aspects for User-Oriented Design. In: INTERNATIONAL CONFERENCE CARTOGRAPHY, 19, 1999, Ottawa. Proceedings... Ottawa: ICC-ICA, 1999.

HAEBERLING, C. Highly Focussed Selected Design Aspects and Graphic Variables for 3D Mountain Maps. In: ICA MOUNTAIN CARTOGRAPHY WORKSHOP, 2004, Catalonia: ICC-ICA, 2004. 
HAEBERLing, C., BAR, H. AND HURNI, L. Proposed Cartographic Design Principles for 3D Maps: A Contribution to an Extended Cartographic Theory. Cartographica. 43/3, (2008) 175-188.

Harrower M. A History of Animated Maps. Disponível em: http://cartography2.org/ Chapters/page12/HistoryMapAnimation.html. Acesso no dia 13/04/2011 ás 00:39.

Marques A. P. da S. et al. Representação Cartográfica Temática Tridimensional do Campus da FCT - Unesp. Anais XIV Simpósio Brasileiro de Sensoriamento Remoto, Natal, Brasil, 25-30 abril 2009, INPE, p. 1811-1818.

Moellering H. Strategies of Real-Time Cartography. Cartographic Journal, The, 1980 - ingentaconnect.com

MONTELLO, D. R. Cognitive Map-Design Research in the Twenieth Century: Theoretical and Empirical Approaches. Cartography and Geographic Information Science, Vol. 29, No. 3, 2002, pp. 283-304

Norma Técnica Copel - NTC. Desenho de Redes De Distribuição. $2^{\mathrm{a}}$ edição Dezembro / 2003.

NERO, M. A.; MEDINA, N. O; SANTOS, R. L. G.; LAPA, R. A.; SILVA, S. F.; SILVA, J. P. M.; BRAZIL, C. R. S. Desenvolvimento de SIG 3D com opesource para a área de distribuição de energia elétrica. Revista Brasileira de Cartografia. $\mathrm{n}^{\mathrm{o}}$ 62(1), março, 2010. SBC, Rio de Janeiro, RJ. Disponible em: < http://www.rbc.ufrj.br/_pdf_62_2010/62_01_3.pdf> Acesso em: 08/02/2013.

PETROVIC, D. 2003. Cartographic Design in 3D Maps. In: International Conference Cartography, 19., 1999. ICC-ICA, 1999.

PETROVIČ, D.; MASERA, P. Analysis of User's Response on 3d Cartographic Presentations. Em: proceeding of the $22^{\text {nd }}$ ICA, International Cartographic Conference, A curunã, Spain in 2005.

SCHMIDT, M. A.; DELAZARI, L. S.. Avaliação de mapas topográficos 3D para navegação virtual. Boletim de Ciências Geodésicas (Online), v. 18, p. 532-548, 2012.

SLUTER C. R., Uma Abordagem Sistêmica para o Desenvolvimento de Projeto Cartográfico como parte do Processo de Comunicação Cartográfica. Portal da cartografia, Londrina, 01 (2008) 1-20. Disponível em <http://www.uel.br/ revistas/uel/index.php/portalcartografia>.

(Recebido em janeiro de 2013. Aceito em abril de 2013.) 